\title{
A study of maternal and fetal outcome in cardiac disease in pregnancy at tertiary care center
}

\author{
Kurra Sai Pujitha*, Sheela S. R., Naga Jyothi S.
}

Department of Obstetrics and Gynecology, Sri Devaraj Urs Medical College, Kolar, Karnataka, India

Received: 08 September 2017

Accepted: 29 September 2017

\section{*Correspondence:}

Dr. Kurra Sai Pujitha,

E-mail: pujitha2466@gmail.com

Copyright: () the author(s), publisher and licensee Medip Academy. This is an open-access article distributed under the terms of the Creative Commons Attribution Non-Commercial License, which permits unrestricted non-commercial use, distribution, and reproduction in any medium, provided the original work is properly cited.

\section{ABSTRACT}

Background: Cardiac disease complicating pregnancy is an indirect cause of maternal mortality. The incidence of cardiac disease during pregnancy has remained stable for many years even with significant decrease in the occurrence of rheumatic heart disease (RHD) as this decrease is being compensated by significant increase of pregnancy in women with congenital heart disease (CHD). Therefore, in this study we aim to analyse the incidence of cardiac disease in pregnancy and to assess the obstetrical outcome.

Methods: A retrospective study carried out in 32 women with cardiac disorders at a tertiary care centre during the period of 5 years.

Results: In the present study the incidence of cardiac disease in pregnancy was observed to be $0.21 \%$. With $62.6 \%$ rheumatic, $21.8 \%$ congenital being and $15.6 \%$ peripartum cardiomyopathy. Among rheumatic valvular heart disease, mitral valve stenosis was most common followed by mitral regurgitation and tricuspid regurgitation. Non-cardiac complications like pre-eclampsia and anaemia were also noted. No of vaginal delivery were higher compared to caesarean (26 versus 6). Adverse perinatal outcomes in form of preterm, NICU admission and perinatal death were also noted.

Conclusions: A cardiac disease has a major impact on pregnancy. It is a multidisciplinary teamwork to have optimal maternal and foetal outcome in women with cardiac disease. Hence, constant vigilance is required throughout antenatal, intrapartum and postpartum period to avoid adverse outcomes.

Keywords: CHD, MS, MR, RHD

\section{INTRODUCTION}

Cardiac disease in a pregnancy is a high-risk pregnancy, which possess a significant challenge to an obstetrician. Cardiac disease in pregnant women most commonly due to RHD, CHD, less commonly due to ischemic heart disease or cardiomyopathy. Though the frequency of RHD has decreased worldwide but still in developing countries like India, RHD is still predominant.

Pregnancy makes a significant impact on cardiovascular system. Around 15-52\% of cardiac abnormalities first diagnosed during routine antenatal check-ups or due to the signs and symptoms caused by physiological changes of pregnancy. ${ }^{1}$

At present $0.2-0.4 \%$ of all pregnancies in western countries are complicated by cardiovascular disease. ${ }^{2}$

Incidence of cardiac disease complicating 1 to $4 \%$ of pregnancies in India. ${ }^{3}$

The most common clinical features of cardiac lesions like breathlessness, pedal oedema, murmurs which mimic normal physiological changes in pregnancy posing a diagnostic difficulty for obstetricians. However, there is 
decreased incidence of cardiac disease in pregnancy due to improved facilities and surgical interventions early in childhood.

The obstetric complications like pre-eclampsia, anaemia, preterm labor, foetal growth restriction further worsen the outcome and complicate the management of pregnancy with cardiac disease.

Pregnancy related complications that compound the heart disease is ignored in the rural setup and patients rarely seek proper early care. ${ }^{4}$

\section{METHODS}

This was a retrospective study carried out at the Department of Obstetrics and Gynecology in collaboration with cardiology department at Sri Devaraj Urs Medical College, Kolar during the period of June 2012 to June 2016.

A total of 32 pregnant women with cardiac disease admitted during the study period were included in the study. All the patients detailed demographic information, diagnosis, course in the hospital, management, maternal and fetal outcome was obtained from our medical records and files.

\section{Inclusion criteria}

Pregnant women with a history of or newly diagnosed cardiac disease were included in the study.

\section{Exclusion criteria}

All conditions mimicking heart disease were excluded. The data collected was statistically analyzed to see the impact of cardiac disease on pregnancy and to evaluate the maternal and fetal outcome.

\section{RESULTS}

A total of 32 pregnant women with cardiac disease were included in the study. Incidence of cardiac disease at our centre was $0.21 \%$. Of the 32 patients, majority of patients were in the age group of $21-25$ years $(50.0 \%)$ and $34.4 \%$ belonged to 18-20 years (as shown in Table 1).

Table 1: Maternal characteristics, age wise distribution.

\begin{tabular}{|ll|}
\hline Maternal age (years) & Number $(\%)$ \\
\hline $18-20$ & $11(34.4)$ \\
\hline $21-25$ & $16(50.0)$ \\
\hline $26-30$ & $02(6.3)$ \\
\hline $31-35$ & $03(9.3)$ \\
\hline
\end{tabular}

Among the 32 pregnant women $56.3 \%$ were primigravida, $34.3 \%$ were second gravida and $9.4 \%$ were gravida 3 or more (as shown in Table 2). Of the 32 women majority were term gestation $(68.8 \%)$ and $9.3 \%$ were pre-term gestation (Table 3).

Table 2: Parity wise distribution.

\begin{tabular}{|ll|}
\hline Parity & Number $(\%)$ \\
\hline Primigravida & $18(56.3 \%)$ \\
\hline Gravida 2 & $11(34.3 \%)$ \\
\hline Gravida 3 and more & $03(9.4 \%)$ \\
\hline
\end{tabular}

Table 3: Maternal characteristics, gestational age wise distribution.

\begin{tabular}{|ll|}
\hline Gestational age & Number $(\%)$ \\
\hline 38 weeks-32 weeks & $05(15.6)$ \\
\hline 37 weeks-36 weeks & $03(9.3)$ \\
\hline$>40$ weeks & $22(68.8)$ \\
\hline
\end{tabular}

Most of the patient in the study had rheumatic heart disease $(62.6 \%)$, followed by congenital heart disease $(21.8 \%)$ and Peripartum cardiomyopathy (15.6\%) as shown in Table 4 . The surgical correction was done in $40.6 \%$ of patients, of which 10 patients underwent surgery prior to pregnancy and 3 during pregnancy due to worsening of the disease, none of the patient had residual disease after surgery (Table 5 and Table 6).

Table 4: Prevalence.

\begin{tabular}{|lll|}
\hline Type of cardiac disease & Number & Percentage \\
\hline Congenital heart disease & 07 & 21.8 \\
\hline Rheumatic heart disease & 20 & 62.6 \\
\hline Peripartum cardiomyopathy & 05 & 15.6 \\
\hline
\end{tabular}

Table 5: Surgical intervention for underlying cardiac disease.

\begin{tabular}{|ll|}
\hline Surgical correction & $13(40.6 \%)$ \\
\hline Prior pregnancy & 10 \\
\hline During pregnancy & 03 \\
\hline
\end{tabular}

Table 6: Type of cardiac surgical interventions.

\begin{tabular}{|ll|}
\hline Surgical correction & No. of patients \\
\hline ASD closure & 04 \\
\hline VSD closure & 01 \\
\hline Mitral valve replacement & 02 \\
\hline PTMC & 06 \\
\hline
\end{tabular}

The most common congenital heart disease seen in the study population was ASD (71.4\%), VSD was seen in 2 patients. The most common lesion in patients with RHD was mitral stenosis (55\%) followed by mitral stenosis and mitral regurgitation $(25 \%)$. Aortic lesions were seen in 2 patients, one with aortic stenosis and one with mitral stenosis with aortic regurgitation (Table 7). The functional class of disease as per NYHA classification in 
present study group is shown in Table 8. Most of the patients had NYHA class II (68.75\%). In study population it was seen that the outcome worsened as the class of the disease increased, complications were more in NYHA class III and IV.

Table 7: Type of lesion.

\begin{tabular}{|lll|}
\hline $\begin{array}{l}\text { Type of lesion } \\
\text { Congenital heart disease (07) }\end{array}$ & \\
\hline ASD & 05 & 71.4 \\
\hline VSD & 02 & 28.6 \\
\hline Rheumatic heart disease (20) & \\
\hline MS & 11 & 55 \\
\hline MR & 02 & 10 \\
\hline MS+MR & 05 & 25 \\
\hline AS & 01 & 5 \\
\hline MS+AR & 01 & 5 \\
\hline
\end{tabular}

Table 8: Functional class of the disease.

\begin{tabular}{|lll|}
\hline NYHA class & Number & Percentage \\
\hline Class I & 06 & 18.75 \\
\hline Class II & 22 & 68.75 \\
\hline Class III & 03 & 9.4 \\
\hline Class IV & 01 & 3.12 \\
\hline
\end{tabular}

Most of patients had vaginal delivery $(81.25 \%)$ and caesarean section was done in 6 patients $(18.75 \%)$ as in Table 9. The labour was of spontaneous onset in $40.6 \%$ of patients and induced in 3 cases $(9.4 \%)$. The indication for induction was post-dated pregnancy and severe preeclampsia. In ten patients' outlet forceps were used to cut short the second stage of labor. The various indications for LSCS were foetal distress, cephalopelvic disproportion and malpresentations. Induction of labor was not done in instrumental and caesarean section group.

Table 9: Mode of delivery.

\begin{tabular}{|l|l|l|}
\hline Mode of delivery & Number & Percentage \\
\hline Vaginal delivery & 26 & 81.25 \\
\hline Spontaneous & 13 & 40.6 \\
\hline Induced & 03 & 9.4 \\
\hline Instrumental deliveries & 10 & 31.3 \\
\hline C-section & 06 & 18.75 \\
\hline
\end{tabular}

The maternal complications (Table 10) were seen in 22 $(68.75 \%)$ pregnant women. The common non-cardiac complications noticed were anaemia $(45.6 \%)$, preterm labor $(27.3 \%)$ and preeclampsia $(18.1 \%)$. The other noncardiac complications seen were eclampsia (2.6\%), abruptio placentae (9\%). Cardiac complications were seen in 7 cases out of which 5 required ICU care. The most common cardiac complication was CCF (2 patients). Pulmonary oedema was seen in one patient with severe pre-eclampsia and two cases of atrial fibrillation were noted. Of the 5 patients requiring ICU care, 4 patients recovered and there was one maternal death $(3.12 \%)$. Cause of the death was severe MS with pulmonary oedema.

Table 10: Maternal complications.

\begin{tabular}{|lll|}
\hline Complications & Number & Percentage \\
\hline Present & 22 & 68.75 \\
\hline Absent & 10 & 31.25 \\
\hline Non-cardiac & & \\
\hline Anaemia & 10 & 45.6 \\
\hline Preeclampsia & 04 & 18.1 \\
\hline Abruptio placentae & 02 & 9 \\
\hline Cardiac & & \\
\hline CCF & 2 & 9 \\
\hline Pulmonary oedema & 1 & 4.5 \\
\hline $\begin{array}{l}\text { Atrial fibrillation } \\
\text { Pulmonary arterial } \\
\text { hypertension }\end{array}$ & 2 & 9 \\
\hline Maternal mortality & 1 & 4.5 \\
\hline
\end{tabular}

The small for gestation was seen in $50 \%$ of babies, prematurity were seen in $15.6 \%$ of babies and the other neonatal complications are shown in Table 11. A total of 20 babies required NICU care and the various indications are shown in Table 11 . There were 2 perinatal deaths, of which one fresh stillborn (at 33 weeks) and one neonatal death (severe birth asphyxia, died after 3 days of birth).

Table 11: Neonatal outcome.

\begin{tabular}{|lll|}
\hline Complications & Number & Percentage \\
\hline SGA & 16 & 50 \\
\hline Apgar score $<7$ at 1 minute & 06 & 18.7 \\
\hline NICU admissions & 20 & 62.5 \\
\hline Birth asphyxia & 3 & \\
\hline MAS/MSAF & 3 & \\
\hline IUGR & 8 & \\
\hline Preterm & 8 & \\
\hline Perinatal mortality & 02 & 6.25 \\
\hline
\end{tabular}

\section{DISCUSSION}

Cardiac disease contributes to be a major risk factor for maternal and neonatal morbidity and mortality. Although the incidence of cardiac disease in pregnancy more or less remain unchanged but various factors leading to cardiac disease during pregnancy widely varies with different study population and study period. The incidence of cardiac disease in pregnancy in our study was $0.21 \%$. As most of the centers in our country being a referral centers, may not reflect the actual prevalence of this medical disorders in pregnancy. It accounts for important cause of maternal mortality in developing countries. ${ }^{5}$

Present study shows the predominant lesion was rheumatic heart disease $(62.6 \%)$ followed by congenital heart disease $(21.8 \%)$ and peripartum cardiomyopathy $(15.6 \%)$. The observations in the present study were 
comparable with other studies done by Sheela et al $(67 \%)$ and Balasaheb $\mathrm{V}$ et al $(73.9 \%)^{6,7}$ However with increasing use of effective antibiotics against streptococcal bacterial cause in the rheumatic fever, the incidence has been greatly reduced.

The most commonly found valvular lesion in the present study was mitral valve disease $(56.3 \%)$ affected by rheumatic fever, followed by aortic valve disease $(6.25 \%)$.

Rheumatic heart disease complicates about $0.3 \%$ to $3.5 \%$ of women in the childbearing period with a global figure of $1 \% .^{8}$ It accounts for about $30 \%$ of cardiac disease during pregnancy in developed countries and $90 \%$ off cardiac disease in developing regions. ${ }^{9,10}$

Out of 32 pregnant women in the present study group $40.6 \%$ underwent surgical intervention for cardiac disease. The results were comparable with studies conducted by Bhatla et al. ${ }^{11}$ Majority of the patients $(87.5 \%)$ belong to NYHA class I and class II. The percentage of patients with NYHA class III and IV was $12.5 \%$ and had a poor outcome. These observations were comparable with the study done by Indira et al. ${ }^{12}$ While studying the mode of delivery 26 patients delivered vaginally out of which 10 patients had instrumental vaginal delivery to cut short the second stage of labor. Six patients had cesarean section, most common indication was previous LSCS.

In the present study maternal complications were observed in 22 patients $(68.75 \%)$ with cardiac disease. Among them the other obstetric complications like anemia was seem in 10 patients, followed by preeclampsia in 4 patients, preterm in 6 patients and abruptio placentae in 2 patients.

We had found one maternal death in the present study and the cause of death was due to pulmonary edema.

In the present study we had 20 NICU admissions, due to birth asphyxia, MSAF, IUGR and preterm. We had found two perinatal mortality, due to prematurity and respiratory distress syndrome. Results were comparable with Prameela et al. ${ }^{13}$

\section{CONCLUSION}

Cardiac disease is a major risk condition, which has adverse effect on pregnancy and its outcome. Rheumatic heart disease is the most common etiological factor even with the advent of antibiotics against streptococcus. However, the incidence more or less remains the same in developing countries like India. Maternal and neonatal morbidity and mortality can be reduced with adequate antenatal check-ups and early detection of cardiac diseases.

\section{Funding: No funding sources}

Conflict of interest: None declared

Ethical approval: The study was approved by the Institutional Ethics Committee

\section{REFERENCES}

1. Uebing A, Steer PJ, Yentis SM, Gatzoulis MA. Pregnancy and congenital heart disease. $\mathrm{Br}$ Med $\mathrm{J}$. 2006;332:401-6.

2. Vera RZ, Carina BL, Claudio B, Renata C, Rafael F, Jean MF. ESC guidelines on the management of cardiovascular diseases during pregnancy. Eu Heart J. 2011;3147-97.

3. Bansode BR. Pregnancy and heart disease. Assoc Physicians Ind. 2010;773-6.

4. Sawhney H, Aggarwal N, Suri V, Vasishta K, Sharma Y, Grover A. Maternal and perinatal outcome in rheumatic heart disease. Int J Gynaecol Obstet. 2003;9-14.

5. Konar H. Medical disorders in pregnancy: who should see the woman?. J Ind Med Assoc. 2004;102:131.

6. Sheela CN, Karanth S, Patil CB. Maternal cardiac complications in women with cardiac disease in pregnancy. Int J Pharm Biomed Res. 2011;261-5.

7. Vijaya BC, Rekha GD, Preeti L. Maternal outcome in heart disease in pregnancy. RRJMHS. 2014;61-6.

8. Mohamed R, Awni G. Maternal and fetal outcome in women with rheumatic heart disease. Arch Gynecol Obstet. 2016;273-8.

9. Siu SC, Sermer M, Colman JM, Alvarez AN, Mercier LA, Morton BC, et al. Prospective multi- center study of pregnancy outcomes in women with heart disease. Circ. 2001;104(5):515-21.

10. Carapetis JR, Steer AC, Mulholland EK, Weber M. The global burden of group A streptococcal diseases. Lancet Infect Dis. 2005;685-94.

11. Bhatla N, Lal S, Behera G, Kriplani A, Mittal S, Agarwal $\mathbf{N}$, et al. Cardiac disease in pregnancy. Int $\mathbf{J}$ Obstet Gynecol. 2003;82:153-9.

12. Indira I, Sunitha K, Jyothi. Study of pregnancy outcome in maternal heart disease. IOSR J Dental Med Sci. 2015;14(7):6-10.

13. Prameela. Clinical study of cardiac disease complicating pregnancy. Int Med J. 2015;115-7.

Cite this article as: Pujitha KS, Sheela SR, Jyothi NS. A study of maternal and fetal outcome in cardiac disease in pregnancy at tertiary care center. Int $\mathbf{J}$ Reprod Contracept Obstet Gynecol 2017;6:5095-8. 